\title{
Implementation of Fiber Optic Sensing System on Sandwich Composite Cylinder Buckling Test
}

\author{
Francisco Peña, ${ }^{1}$ W. Lance Richards, ${ }^{2}$ Allen R. Parker, ${ }^{3}$ Anthony Piazza ${ }^{4}$ \\ NASA Armstrong Flight Research Center, Edwards, CA 93523, USA \\ Marc R. Schultz ${ }^{5}$ \\ NASA Langley Research Center, Hampton, VA 23681, USA \\ Michelle T. Rudd ${ }^{6}$ \\ NASA Marshall Space Flight Center, Huntsville, AL 35811, USA \\ Nathaniel W. Gardner ${ }^{7}$ \\ Analytical Services \& Materials, Inc., Hampton, VA 23666, USA \\ Mark W. Hilburger ${ }^{8}$ \\ NASA Langley Research Center, Hampton, VA 23681, USA
}

\begin{abstract}
The National Aeronautics and Space Administration (NASA) Engineering and Safety Center Shell Buckling Knockdown Factor Project is a multicenter project tasked with developing new analysis-based shell buckling design guidelines and design factors (i.e., knockdown factors) through high-fidelity buckling simulations and advanced test technologies. To validate these new buckling knockdown factors for future launch vehicles, the Shell Buckling Knockdown Factor Project is carrying out structural testing on a series of large-scale metallic and composite cylindrical shells at the NASA Marshall Space Flight Center (Marshall Space Flight Center, Alabama).

A fiber optic sensor system was used to measure strain on a large-scale sandwich composite cylinder that was tested under multiple axial compressive loads up to more than $850,000 \mathrm{lb}$, and equivalent bending loads over 22 million in-lb. During the structural testing of the composite cylinder, strain data were collected from optical cables containing distributed fiber Bragg gratings using a custom fiber optic sensor system interrogator developed at the NASA Armstrong Flight Research Center. A total of 16 fiber-optic strands, each containing nearly 1,000 fiber Bragg gratings, measuring strain, were installed on the inner and outer cylinder surfaces to monitor the test article global structural response through high-density real-time and posttest strain measurements. The distributed sensing system provided evidence of local epoxy failure at the attachment-ring-to-barrel interface that would not have been detected with conventional instrumentation. Results from the fiber optic sensor system were used to further refine and validate structural models for buckling of the large-scale composite structures. This paper discusses the techniques employed for real-time structural monitoring of the composite cylinder for structural load introduction and distributed bending-strain measurements over a large section of the cylinder by utilizing unique sensing capabilities of fiber optic sensors.
\end{abstract}

\footnotetext{
${ }^{1}$ Aerospace Engineer, Aerostructures Branch, P.O. Box 273, Edwards, California, Mail Stop 48201B.

${ }^{2}$ Chief Engineer, NASA Engineering and Safety Center (NESC), P.O. Box 273, Edwards, California, Mail Stop 2004.

${ }^{3}$ Systems Engineer, Sensors and Systems Development Branch, P.O. Box 273, Edwards, California, Mail Stop 48201B.

${ }^{4}$ Instrumentation Specialist, Aerostructures Branch, P.O. Box 273 Edwards, California, Mail Stop 48201B.

${ }^{5}$ Research Aerospace Engineer, Structural Mechanics and Concepts Branch, 8 West Taylor St, Mail Stop 190, AIAA Senior Member.

${ }^{6}$ Aerospace Engineer, Dynamics, Loads \& Strength Branch, 4600 Rideout Rd., EV31, AIAA Member.

${ }^{7}$ VIC 3D Specialist, Structural Materials and Concepts Branch, 8 West Taylor St., Mail Stop 190.

${ }^{8}$ Senior Research Engineer, Structural Mechanics and Concepts Branch, 8 West Taylor St, Mail Stop 190, AIAA Senior Member.
} 


\section{Nomenclature}

$\begin{array}{ll}\text { 2D } & =\text { two-dimensional } \\ \text { CTA8.1 } & =\text { Cylinder Composite Test Article 8-foot-diameter design 1 } \\ \text { DIC } & =\text { digital image correlation } \\ \text { FBG } & =\text { fiber Bragg grating } \\ \text { FOSS } & =\text { fiber optic sensing system } \\ \text { IML } & =\text { inner mold line } \\ \text { NASA } & =\text { National Aeronautics and Space Administration } \\ \text { OML } & =\text { outer mold line } \\ P_{c r} & =\text { critical buckling load } \\ \text { SBKF } & =\text { Shell Buckling Knockdown Factor Project } \\ w & =\text { digital image correlation radial displacement } \\ \varepsilon_{\mathrm{C}}, \varepsilon_{\mathrm{D}}, \varepsilon_{\mathrm{A}} & =\text { circumferential, diagonal and axial strain, respectively } \\ \varepsilon_{\mathrm{OML}}, \varepsilon_{\mathrm{IML}} & =\text { outer mold line strain and inner mold line strain, respectively } \\ \varepsilon_{1}, \varepsilon_{2} & =\text { major and minor principal strains, respectively } \\ \varepsilon_{b} & =\text { bending strain } \\ \varepsilon_{\mathrm{x}}, \varepsilon_{\mathrm{y}}, \varepsilon_{\mathrm{xy}}, \varepsilon_{\mathrm{yx}}, & =\text { strains relative to two reference orthogonal orientations } \\ \gamma_{x y} & =\text { shear strain in reference orthogonal orientations } \\ \theta_{A}, \theta_{C}, \theta_{D} & =\text { angle-to-reference orientation } \\ \theta_{p} & =\text { principal strain angle } \\ \text { Subscripts } & \\ C, D, A & =\text { reference orientations, circumferential, diagonal and axial, respectively } \\ i & =\text { reference to index } \\ x, y & =\text { reference orthogonal orientations, circumferential and axial, respectively }\end{array}$

\section{Introduction}

$\mathrm{T}_{\mathrm{B}}^{\mathrm{H}}$

HE National Aeronautics and Space Administration (NASA) Engineering and Safety Center (NESC) Shell Buckling Knockdown Factor (SBKF) project is a multicenter project with the goal of revising buckling design guidelines for selected metallic and composite launch-vehicle shell structures. As part of this effort, several large-scale structural buckling tests will be used to validate high-fidelity buckling simulations used in the development of new buckling knockdown factors. The first composite shell that was tested as part of SBKF was an eight-foot diameter and 10-foot tall sandwich composite cylinder that was fabricated by Northrop Grumman Corporation (Falls Church, Virginia) and was designated "Cylinder Composite Test Article 8-foot-diameter design 1" (CTA8.1). See Ref. [1] for a detailed discussion of this test. This cylinder underwent a series of subcritical axial compression, and combined compression and bending load cases prior to the final load sequence of axial compression up to buckling failure. The sandwich composite cylinder was potted into two interface rings (top and bottom) using an epoxy potting compound and tested in a self-reacting load system. The system applied load to the cylinder through a top and bottom load-introduction structure, as shown in Fig. 1, with eight hydraulic actuators. The load system transferred the load to the composite cylinder through the interface rings. Interface ring bolts were also present as a failsafe measure in case the epoxy potting material failed during testing. During the load sequences, the axial compression loads ranged to more than 850,000 lb, and the equivalent combined compression and bending loads ranged to more than 22 million in-lb. Axial load sequences were executed by applying uniform load to all hydraulic actuators. Combined compression and bending loads were applied by linearly varying loads from $20 \%$ of predicted critical load applied load at a designated circumferential position, to zero applied load at $180^{\circ}$ circumferential offset. See Ref. [1] for a detailed discussion of this test. 


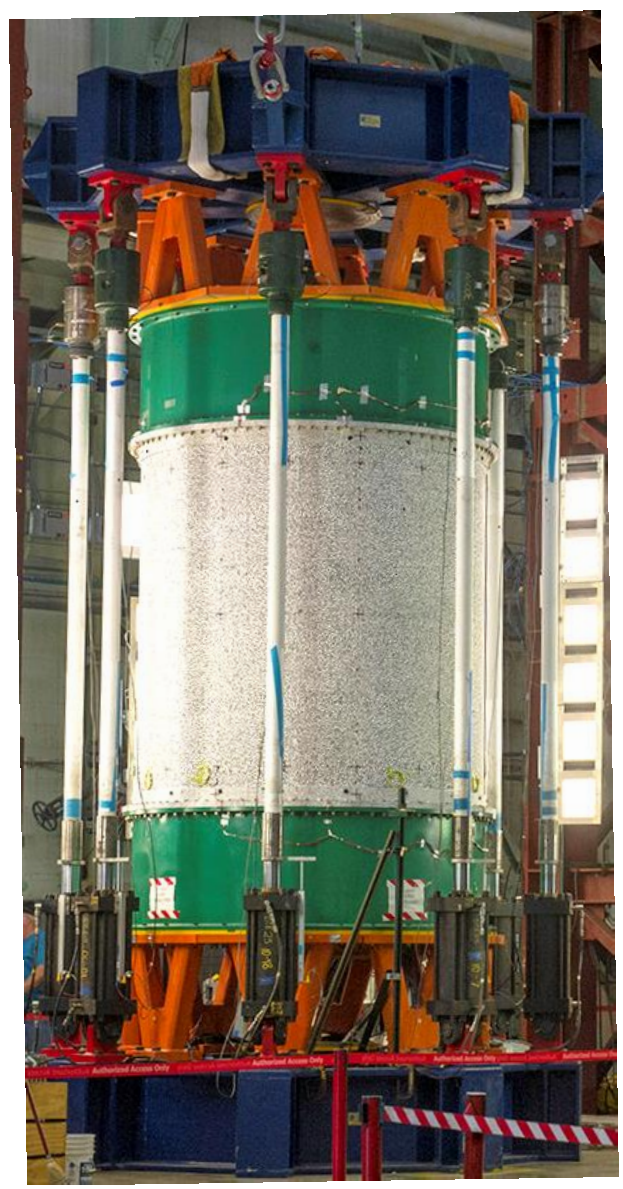

Fig. 1. The CTA8.1 test assembly.

Various types of instrumentation were used to characterize the structural response to applied load during the structural testing of the CTA8.1. Traditional measurements from displacement transducers, electrical-resistance strain gages, and load cells, along with low-speed and high-speed digital image correlation (DIC) based displacement measurements, audio/video recording, and distributed fiber optic sensing system (FOSS) strain data were collected. Approximately 300 traditional strain and displacement sensors were split between the inner mold line (IML) and the outer mold line (OML). Additionally, both low-speed and high-speed DIC covered essentially the entire OML and low-speed DIC covered two small portions of the IML. The particular FOSS, which was developed at the NASA Armstrong Flight Research Center (AFRC) (Edwards, California), can be used to interrogate optical fiber with a series (up to 1,000) of distributed fiber Bragg gratings (FBG) to provide real-time strain data. During structural testing, the FOSS was able to simultaneously and continuously interrogate 1640 -foot optical fibers at 0.5 -inch intervals, providing nearly 16,000 strain sensor readings per scan at $12 \mathrm{~Hz}$ in this application. The AFRC FOSS can operate in stand-alone mode, which is used for flight applications, or in remote-control mode, in which a laptop is connected to provide monitoring and control. A centralized software interface combines all functions into a suite of applications to fully utilize the FOSS. The high spatial resolution enables dense strain contours to be generated to better characterize the strain response of a structure in real time. The FOSS provides 100 times the number of strain measurements at $1 / 100^{\text {th }}$ the total sensor weight when compared to conventional electrical-resistance strain gage implementations, as stated in Ref. [2].

Many traditional sensors such as displacement potentiometers and electrical-resistance strain gages provide essentially point measurements. Care must therefore be taken to include such sensors in specific regions of interest, which process can be costly and cumbersome if high-density strain or displacement measurements are required for test monitoring. Conversely, full-field photogrammetry techniques such as DIC can have relatively lower measurement resolution that may not capture high-density strain gradients. Additionally, DIC requires an unobstructed view of the surface being measured, and leadwires to traditional sensors can disrupt direct viewing of the surface. The 
FOSS, therefore, can be advantageous when high accuracy and high measurement density are desired. In the case of compression loading of shell structures, it is common to have fairly complex prebuckling and buckling deformation patterns. Slight geometrical or loading imperfections can significantly change these deformation patterns, so it can be difficult know specifically where instrumentation is required before testing begins.

This paper discusses the techniques employed for real-time structural monitoring of the composite cylinder. Load introduction to the structure was monitored by incorporating 144 individual fiber-optic rosettes around the upper and lower circumference of the cylinder, on both the OML and IML surfaces. Each rosette provided qualitative principal strain magnitudes and strain orientations. The AFRC FOSS data were compared against audio data collected by a microphone in order to help determine the cause of a series of "popping" noises that were heard during subcritical compression loads, which noises were believed to be due to local epoxy failure at the attachment-ring-to-barrel interface. These features would not have been detected with conventional instrumentation. Experimental data were also obtained through a network of five near-continuous axial stations along the height of the structure and eight near-continuous circumferential stations of fiber Bragg gratings distributed on both the OML and the IML of the cylinder. The distributed fiber Bragg gratings covering a large area of the test article enabled real-time monitoring of the structural response of the test articles. The large coverage area increased the probability of capturing bending strain during buckling; pre-test buckling predictions and actual buckling can vary, making it challenging to locate conventional surface-mounted instrumentation. The FOSS data supplemented the use of DIC techniques by providing localized bending-strain data at the point of maximum deflection leading up to the collapse of the test article.

\section{Fiber Optic Sensor Layout}

The primary objective of the FOSS layout was to monitor the load introduction to the composite cylinder by measuring strains near the top and bottom attachment rings. Continuous circumferential fiber optic strain sensors were installed on the test article approximately one inch below the top interface ring and one inch above the bottom interface ring on both the OML and IML. Adjacent fiber optic strain sensors were then installed near the interface rings with varying orientations in order to provide fiber optic strain sensor rosette measurements (see Fig. 2), which are used to provide qualitative principal strain magnitudes and strain orientations.

The secondary objective of the FOSS layout was to characterize the global strain response of the test article. Eight essentially continuous axial and five essentially continuous circumferential stations were installed on both the OML and IML. The axial and circumferential stations were not completely continuous due to the interleaving of multiple fibers; a one-inch bend radius was used in the fiber optic sensor layout to minimize light loss. The fiber optic strain sensor layout in circumferential and axial orientations as well as the sensor installation on the test article is provided in Fig. 2. Throughout this paper the circumferentially-oriented fibers are aligned horizontally, and the axially-oriented fibers are aligned vertically. The locations of the interface rings with the interface ring bolts are also shown in Fig. 2. It should be noted that all optical fibers were installed in a mirrored configuration on the OML and IML so that membrane and bending strains could be calculated.

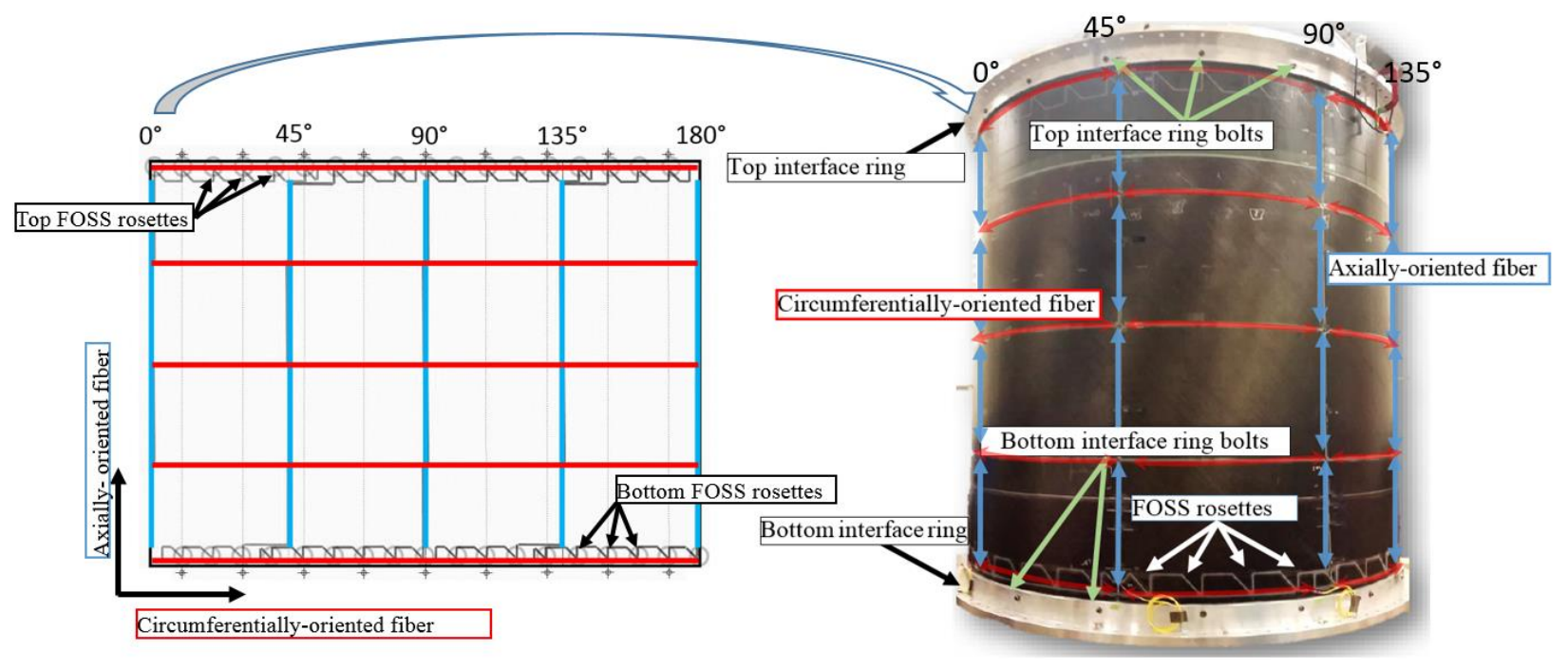

Fig. 2. The FOSS instrumentation layout on the outer mold line. 


\section{Results and Discussion}

During structural testing of CTA8.1, the FOSS was able to simultaneously and continuously interrogate 1640 -foot optical fibers at 0.5 -inch intervals, providing nearly 16,000 strain sensor readings per scan. A summary of the data collected from the FOSS is presented in the following sections.

\subsection{Strain Measurements near Interface Rings}

Fiber optic strain sensing strain rosettes were installed on the test article adjacent to both of the interface rings in order to monitor the boundary conditions near the loading ring attachment points. A partial diagram of the FOSS strain rosette relative to the top interface ring bolt is presented in Fig. 3. Each interface ring had 18 radial bolts (every $20^{\circ}$ around the circumference) (Fig. 2 and Fig. 3). Fiber optic strain sensing strain rosettes were installed in line with and midway between bolts in order to interrogate the influence of the bolts on the introduction of the load. Thirty-six FOSS strain rosettes (one every $10^{\circ}$ ) thus were used on each of the top and bottom IML and OML, for a total of 144 FOSS strain rosettes. The FOSS strain rosette measurements were used to provide a qualitative measurement of the load introduction onto the test article and to verify that the loading was applied as intended: either uniform compression or varying for applied combined compression and bending cases.

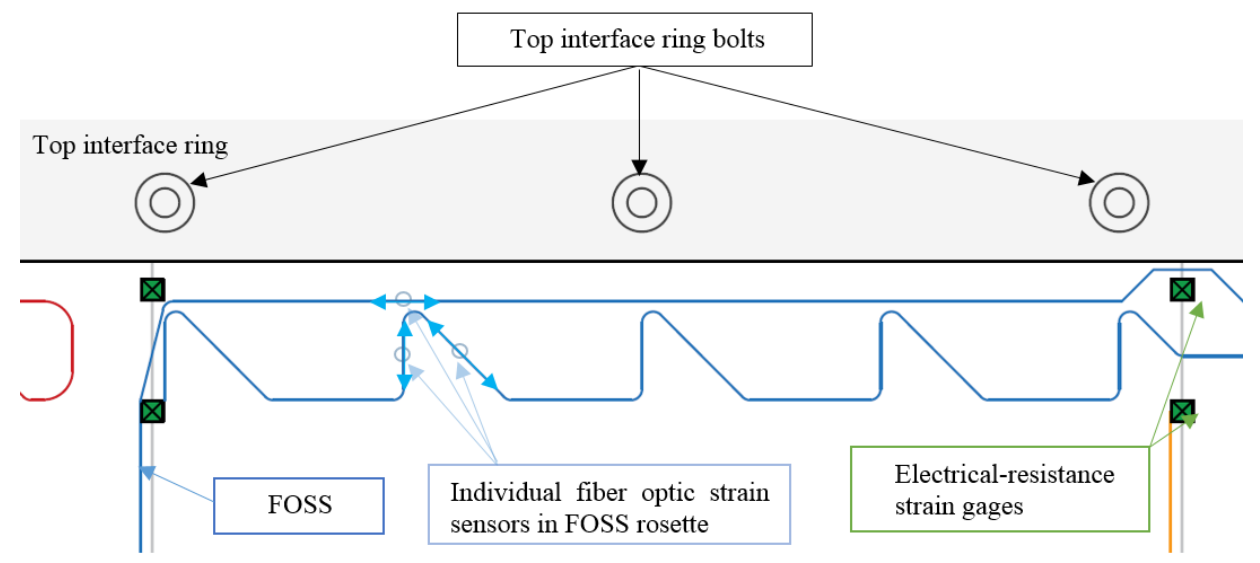

Fig. 3. The FOSS rosette layout.

A valid strain rosette requires three strain measurements in three unique orientations at a single point. Due to a trade-off between fiber optic cable bend radiuses versus signal loss, the bend radius of the FOSS layout was limited to 0.5 inch. This relatively large bend radius caused each leg of the FOSS strain rosette to be spaced approximately 2.5 inches from the next. The spacing between the individual legs of a rosette might not be a problem in areas of low strain gradients, but accuracy is lost in areas having high strain gradients. High strain gradients were observed at both interface rings and are discussed below. The FOSS strain rosettes thus are used for qualitative purposes only.

Each FOSS strain rosette leg measured strains in one of three unique orientations (circumferential $\theta_{C}$, axial $\theta_{A}$, and at a diagonal $45^{\circ}$ angle $\theta_{D}$ ) as shown in Fig. 3 and Fig. 4(a). Data from these rosettes were then processed to calculate the principal strain magnitudes $\left(\varepsilon_{1}\right.$ and $\left.\varepsilon_{2}\right)$ and the principal strain angle $\left(\theta_{p}\right)$.

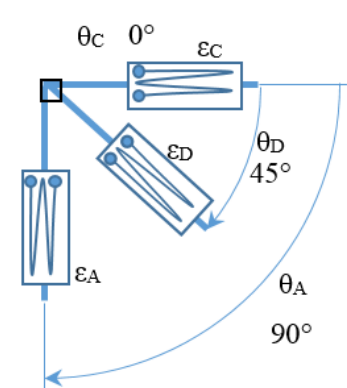

(a)

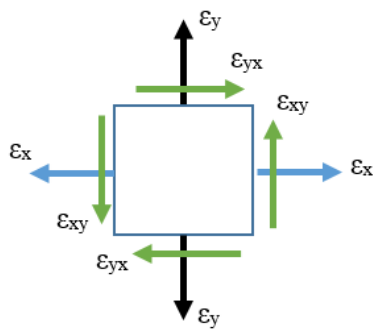

(b)

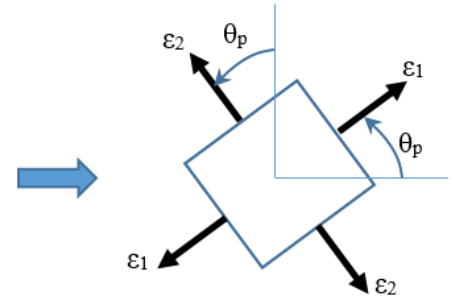

(c)

Fig. 4. (a) three-element rectangular rosette of a traditional strain gage; (b) element strains at given coordinate; and (c) element strain transformed to principal coordinate. 
It can be shown (e.g., by Dally and Riley, Ref. [3]) that Eq. (1) is the strain transformation matrix, which is used to transform strain from the three independent angle orientations $\left(\theta_{C}, \theta_{D}, \theta_{A}\right)$ into strain in two orthogonal orientations and to quantify shear strain relative to the two orthogonal orientations:

$$
\left[\begin{array}{l}
\varepsilon_{C} \\
\varepsilon_{D} \\
\varepsilon_{A}
\end{array}\right]=\left[\begin{array}{lll}
\cos ^{2}\left(\theta_{C}\right) & \sin ^{2}\left(\theta_{C}\right) & \sin \left(\theta_{C}\right) \cos \left(\theta_{C}\right) \\
\cos ^{2}\left(\theta_{D}\right) & \sin ^{2}\left(\theta_{D}\right) & \sin \left(\theta_{D}\right) \cos \left(\theta_{D}\right) \\
\cos ^{2}\left(\theta_{A}\right) & \sin ^{2}\left(\theta_{A}\right) & \sin \left(\theta_{A}\right) \cos \left(\theta_{A}\right)
\end{array}\right]\left[\begin{array}{c}
\varepsilon_{x} \\
\varepsilon_{y} \\
\gamma_{x y}
\end{array}\right]
$$

where $\varepsilon_{C}$ is a strain measurement oriented in the circumferential direction, $\varepsilon_{D}$ is a strain measurement oriented diagonal $45^{\circ}$ from the circumferential direction toward the axial direction, and $\varepsilon_{A}$ is a strain measurement in the axial direction; see Fig. 4(a). The reference angles for each leg of the rosette are $\theta_{C}, \theta_{D}$ and $\theta_{A}$, which are also illustrated in Fig. 4(a). The axial and circumferential directions were chosen as the two reference orthogonal orientations, therefore $\varepsilon_{x}$ is the circumferential strain, $\varepsilon_{y}$ is the axial strain, and $\gamma_{x y}$ is the shear strain relative to the circumferential and axial orientation and is the sum of shear terms $\varepsilon_{x y}$ and $\varepsilon_{y x}$ in the strain tensor; see Fig. 4(b). Once the two orthogonal strains $\left(\varepsilon_{x}\right.$ and $\left.\varepsilon_{y}\right)$ and shear strain $\left(\gamma_{x y}\right)$ are obtained, the principal strain magnitudes $\left(\varepsilon_{1}\right.$ and $\left.\varepsilon_{2}\right)$ and principal strain angle $\left(\theta_{p}\right)$ can be calculated (Ref. [3] and Ref. [4]) using Eqs. (2) and (3).

$$
\begin{gathered}
\varepsilon_{1,2}=\frac{\varepsilon_{x}+\varepsilon_{y}}{2} \pm \sqrt{\left(\frac{\varepsilon_{x}-\varepsilon_{y}}{2}\right)^{2}+\left(\frac{\gamma_{x y}}{2}\right)^{2}} \\
\tan \left(2 \theta_{p}\right)=\frac{\gamma_{x y}}{\varepsilon_{x}-\varepsilon_{y}}
\end{gathered}
$$

An illustration of element strain transformed to principal coordinate is illustrated in Fig. 4(c). Equation (2) is used to compute the principal strain magnitudes and Eq. (3) is used to compute the principal strain angle. The primary loading condition being axial compression, the minor principal strain $\left(\varepsilon_{2}\right)$ was monitored since it corresponded to the largest compressive strain. (The axial leg of a FOSS strain rosette would have the largest effect on the minor principal strain.) An example of the real-time minor principal strain indicator along the aft IML for a uniform compressive load of 50\% $P_{c r}$ (critical buckling load, calculated using linear eigenvalue finite-element analysis as the buckling load of the nominal cylinder design) is presented in Fig. 5. The average minor principal strain from the FOSS strain rosette was $-1,365$ microstrain. Variations in the minor principal strains may be due to a combination of FOSS measurement system uncertainty, large rosette size and local stress or strain concentrations from the attachment-ring interface that may have affected one or more of the three independent legs of the FOSS strain rosettes.

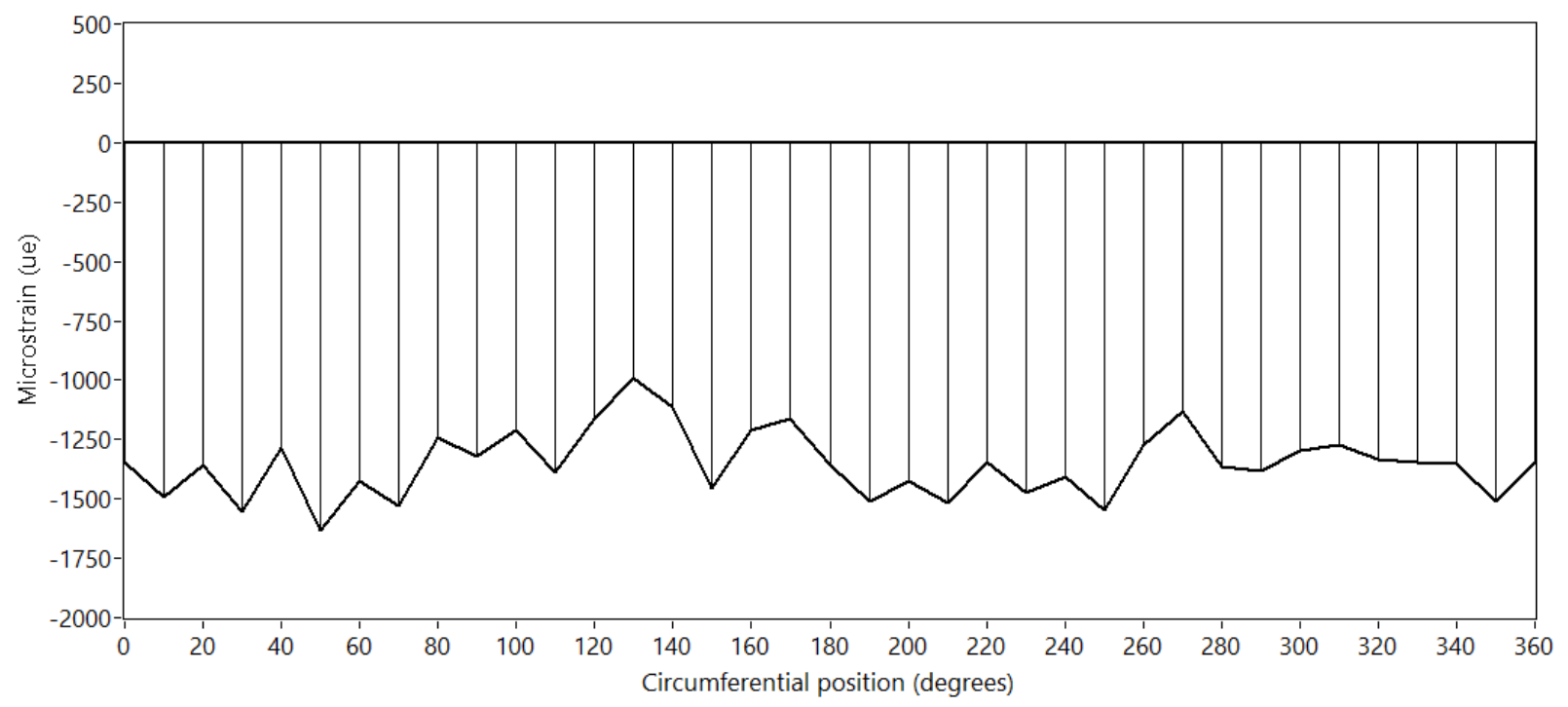

Fig. 5. An example of the real-time minor principal strain indicator along the aft inner mold line for a uniform compressive load of $50 \% P_{c r}$. 
An example of the real-time minor principal strain indicator along the aft IML for a compression and bending load case with maximum applied compression at the $180^{\circ}$ circumferential position is presented in Fig. 6 . In this figure, it is seen that the minor principal strain reaches maximum compression at the $180^{\circ}$ circumferential position. It is evident that the load tapers off as a function of circumferential position and reaches its lowest compressive strain at the $0^{\circ}$ circumferential position and the $350^{\circ}$ circumferential position. These rosette measurements indicate that the bending loads with maximum compression near $180^{\circ}$ were imparted to the cylinder as intended. Variations in the minor principal strains may be due to a combination of measurement uncertainty and local stress or strain concentrations from the attachment-ring interface that may have affected one or more of the three independent legs of the FOSS strain rosettes.

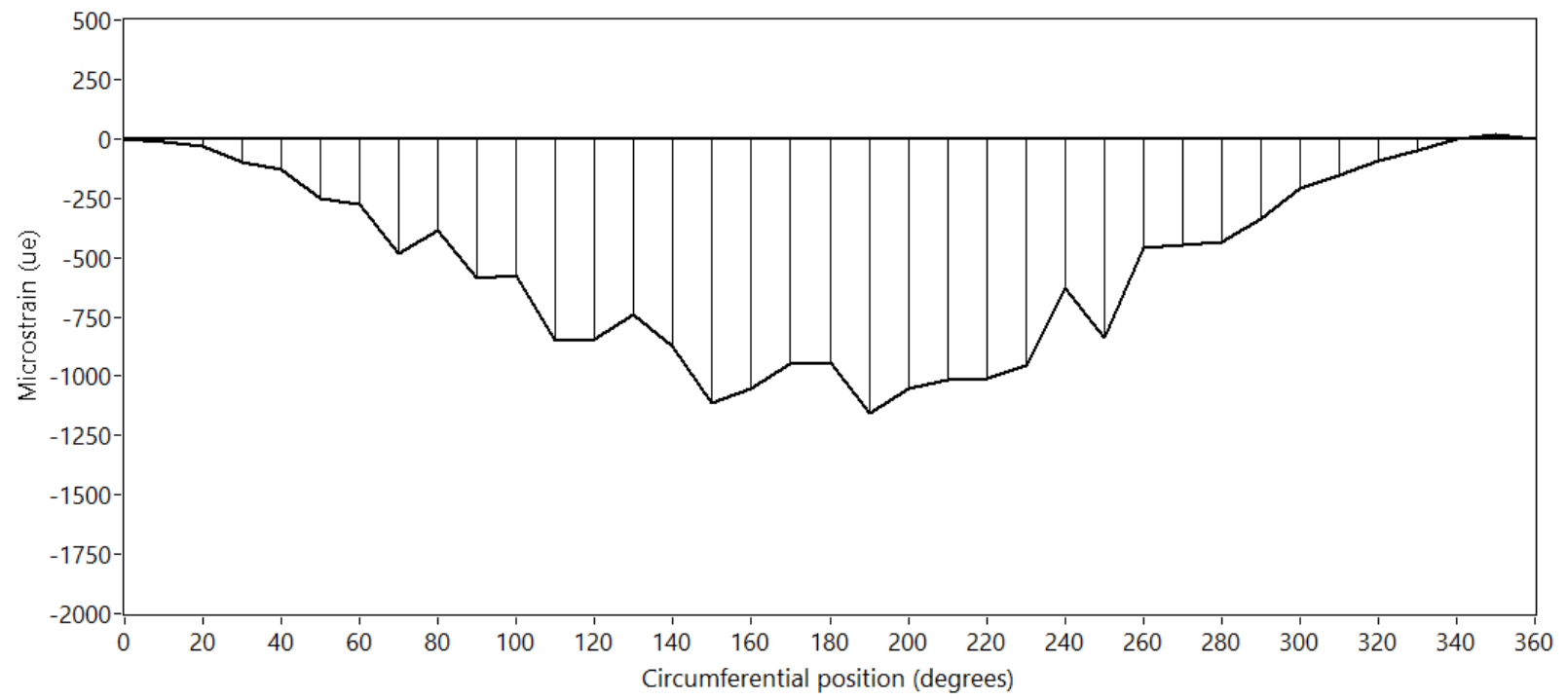

Fig. 6. An example of the real-time minor principal strain indicator along the aft inner mold line for a compression and bending load case with maximum applied compression at the $180^{\circ}$ circumferential position.

\subsection{Interface-Ring-to-Bolt-Interface Strain Distribution}

During axial load cases ranging from $20 \%$ to $50 \% P_{c r}$, several "popping" noises were heard by test engineers. These audible "pops" were found to correlate with localized abrupt increases in strain radiating from multiple sources near the interface-ring-to-bolt interface. An illustration of the interface-ring region of the CTA8.1 test-article assembly is shown in Fig. 7.

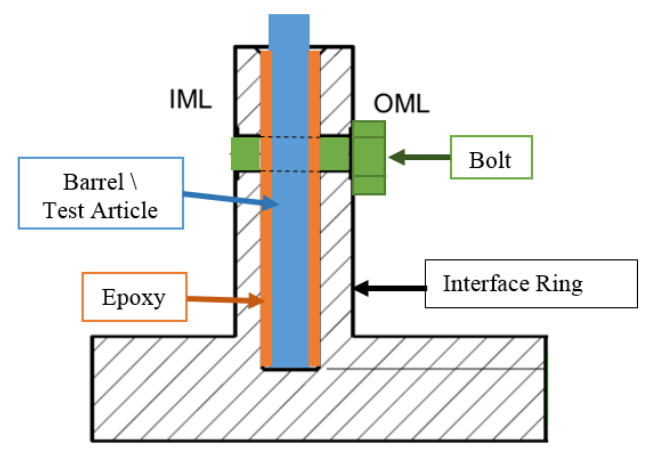

Fig. 7. Cross section of the interface-ring region of the CTA8.1 test-article assembly.

Data of a single FBG on a circumferential fiber at the $30^{\circ}$ circumferential position and adjacent to the interface ring, data from the axial load cells, and the normalized audio data from a microphone are overlaid in Fig. 8 and plotted against sample number (equivalent to time). The data presented in Fig. 8 were collected from multiple load sequences ranging from $20 \%$ to $50 \% P_{c r}$. Each load sequence included planned hold periods in order to allow test engineers to evaluate the state of the structure under load. The 20\%, 30\%, 40\% and 50\% $P_{c r}$ compression load sequences were executed over three days of testing, therefore the data sample number, rather than time, is provided. 


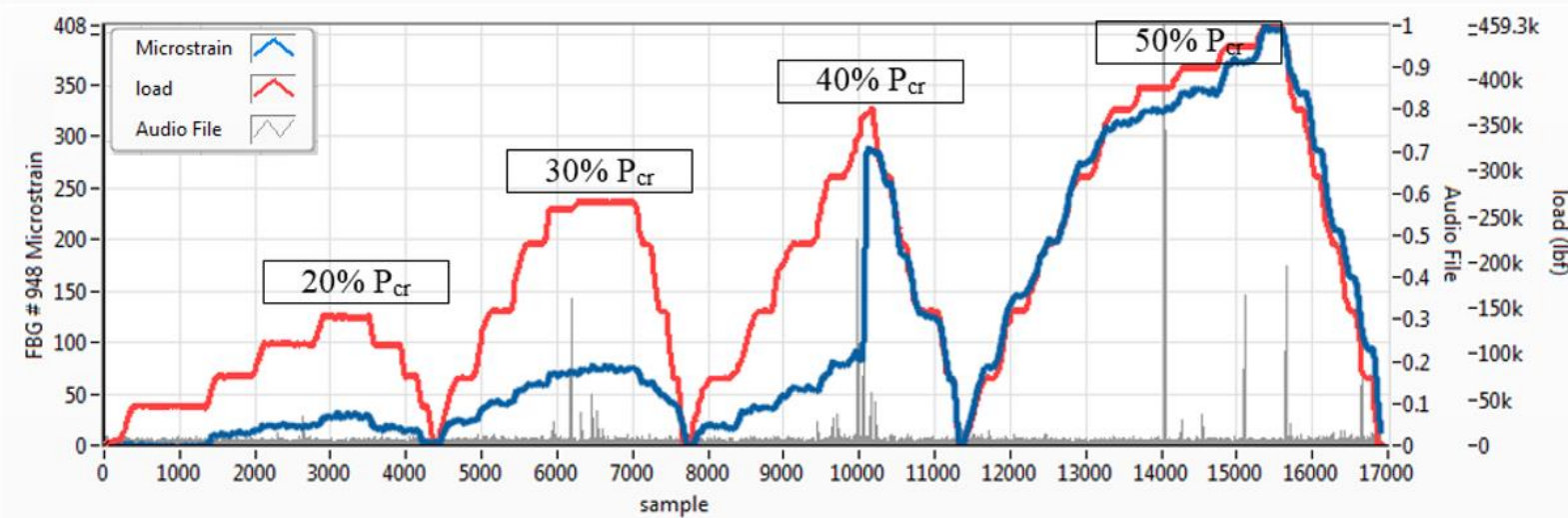

Fig. 8. Example of a "pop," recorded microstrain at the $30^{\circ}$ circumferential position near the interface ring (blue), recorded load profile from load sequences $20 \%$ to $50 \% P_{c r}($ red), and normalized microphone audio file (gray).

The data presented in Fig. 8 indicate that prior to sample 10,000 the amount of strain (blue) experienced by the barrel was essentially proportional to the applied load (red). At approximately sample 10,000, an abrupt increase in strain occurred, without an abrupt change in applied load, and an audible "pop" was recorded. After sample 10,000, the relationship between applied load and strain changed. These sensor readings were not necessarily an indication of substrate damage directly underneath the sensor, but an indication that the local stiffness changed, which resulted in a change in the load field that was observed by the sensor. It was assumed that the material failure was localized since the results of the event were not captured by instrumentation elsewhere on the structure. These local damage events did not impact the load-carrying capability of the global structure. Additional audio events occurred throughout testing that did not impact the individual strain sensor at circumferential position $30^{\circ}$ (Fig. 8).

The distributed strain data from FOSS can be used to create two-dimensional (2D) contour plots of the strain magnitude plotted against both the sensor location around the circumference of the barrel and against the acumulated sample number indicating axial load case ( ranging from $20 \%$ to $50 \% P_{c r}$ ). As an example, such a 2D contour plot for circumferential hoop strain gradients around the aft OML circumference is shown in as Fig. 9, in which the contour indicates the strain level, the horizontal axis indicates the hoop sensor number (proportional to the circumferential position), and the vertical axis indicates the sample number (relating to the load sequence). Additionally, the fiber layout at the top of Fig. 9 indicates the circumferential position of the end-ring bolts and the FOSS rosettes. Comparing the circumferential positions of the high-strain (red) regions with the bolt holes indicates that the strain gradients were radiating from the interface-ring-bolt locations. At low sample numbers in low load levels, the strains around the circumference are reasonably uniform; however, the strains at the bolt locations increase, sometimes suddenly, as the load level increases. The first of these sudden changes in strain appears to occur at a sample number 3,000, and is seen most pronounced at sensor numbers near 50. Additional sudden increases in strain occur between sample numbers 6,000 and 7,000, and 10,000 and 14,000. It was believed that the circumferential strain gradients shown in Fig. 9 were indications that the bond between the epoxy potting and the composite barrel failed (in shear), resulting in a load path change. The epoxy initially provided a large area around the circumference of the barrel through which to distribute load. As the epoxy failed, the attachment ring bolts were left to carry the axial load. In comparison to the epoxy contact area, the bolt contact area was much smaller and caused high stress near the bolt-to-attachment-ring interface. 


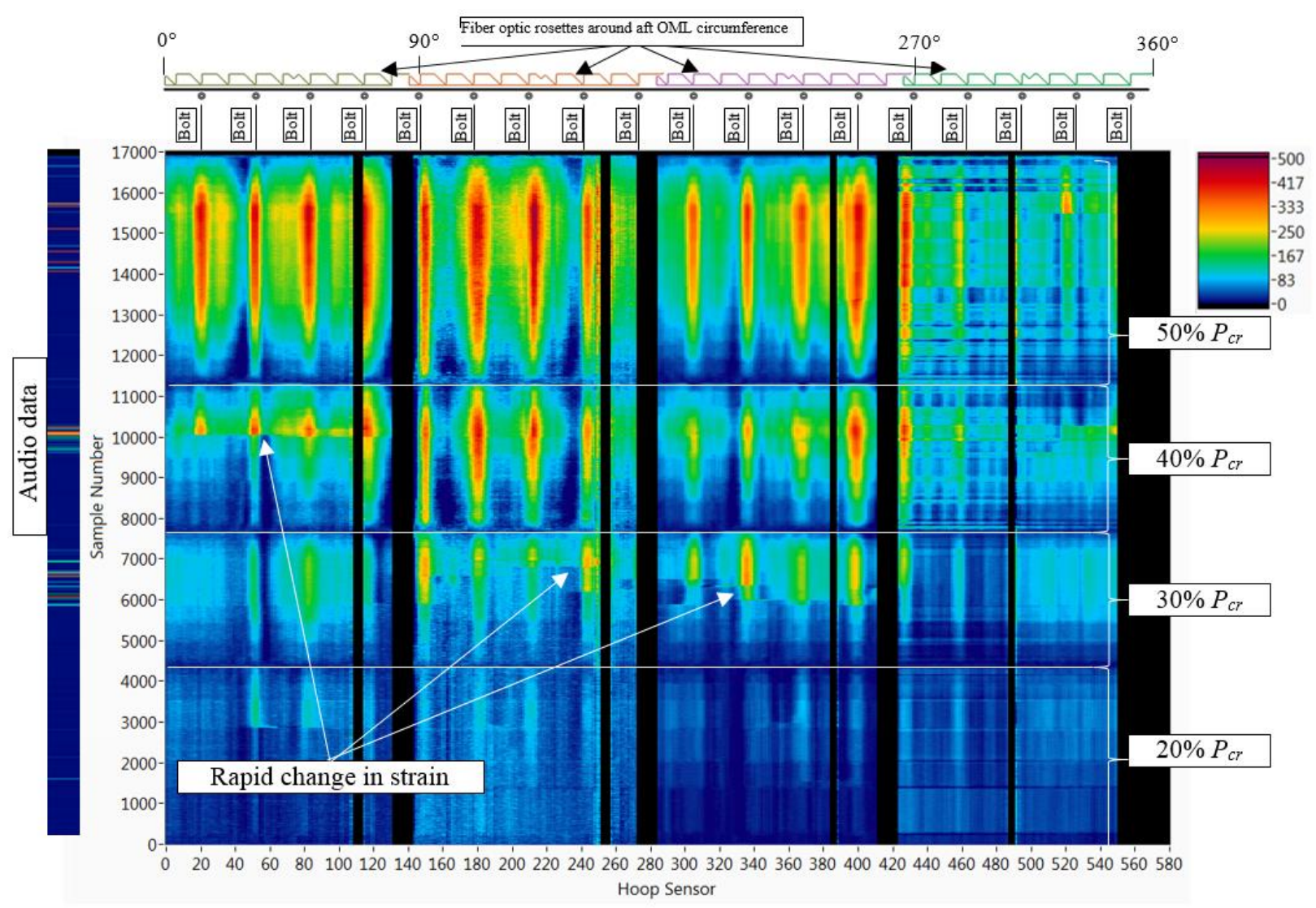

Fig. 9. Two-dimensional intensity plot of hoop strain (color ramp) above the bottom interface ring plotted around circumference (x-axis) versus sample number (y-axis) for load sequences from $20 \%$ to $50 \%$ of $P_{c r}$.

\subsection{Global Strain Measurements}

During CTA8.1 testing of the composite barrel, the FOSS unit provided nearly 16,000 individual fiber optic strain measurements. Each sensor was assigned a circumferential angle position and a vertical height position on the test article. The circumferential angle position was plotted in the $x$-axis while the vertical height position of a sensor was plotted in the $y$-axis; the color intensity is based on the magnitude of the strain measurements.

An example of the real-time 2D scatter plot displays of the distributed strain measurements data on the both IML at loads of 20\%, 30\%, 40\%, and 50\% $P_{c r}$, is presented in Fig. 10(a)-(e). Two independent color palettes were used so that both of the strain gradients in both the circumferential direction (tension strain) and the axial direction (compression strain) could be discerned. Since the applied loads were purely compressive, the tensile hoop strains were a result of Poisson's effect, and were therefore of smaller magnitude and opposite sign to the axial compressive strain. As shown in Fig. 10, the axial strains are plotted on a color scale of increasing compression from white to blue, and the hoop strains are plotted on a color scale of increasing tension from white to red. 


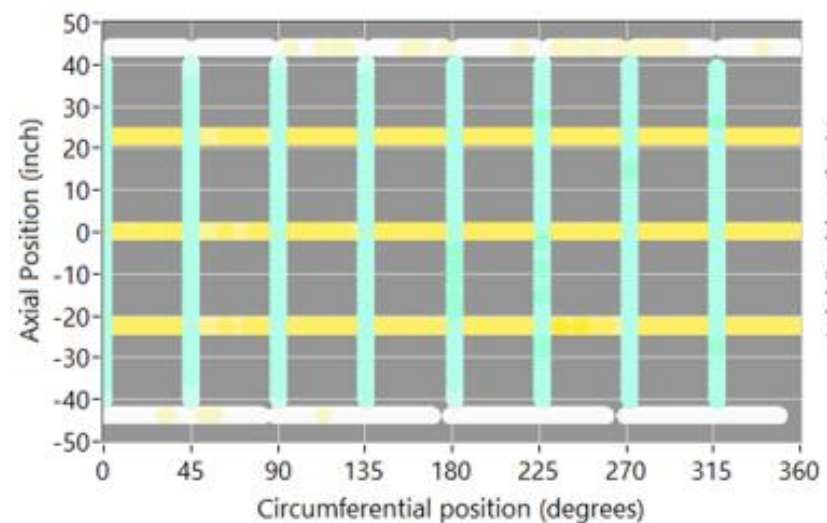

(a)

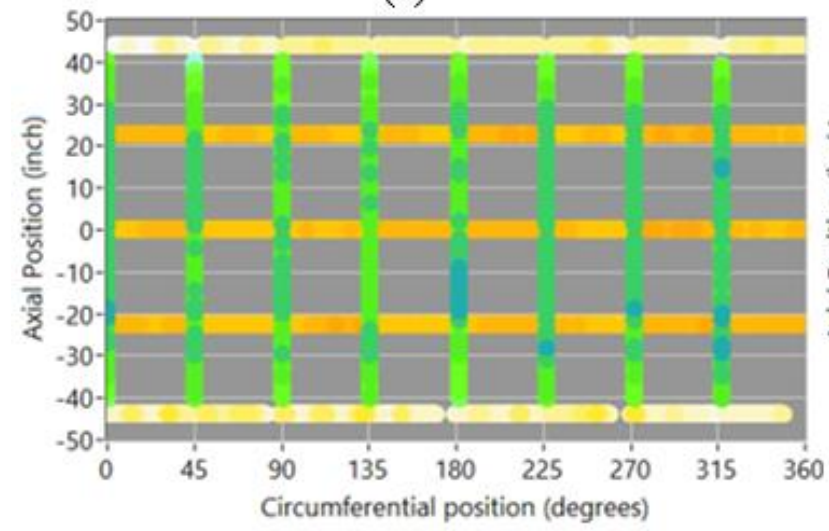

(c)

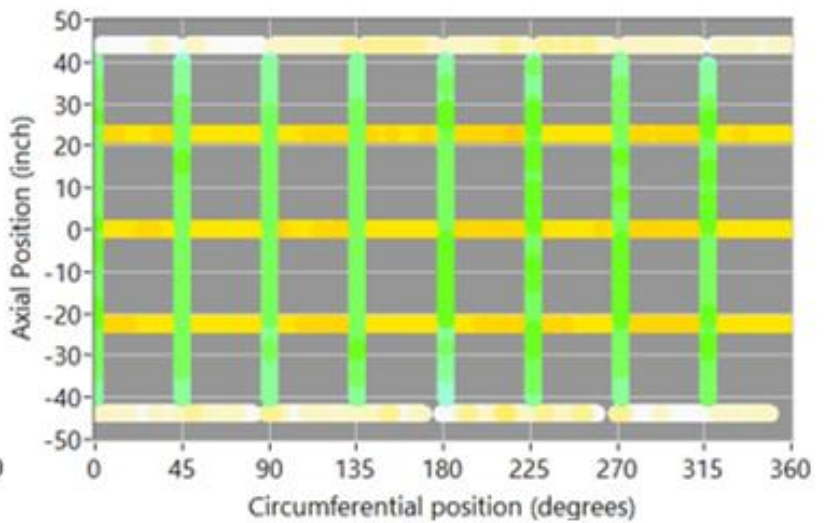

(b)

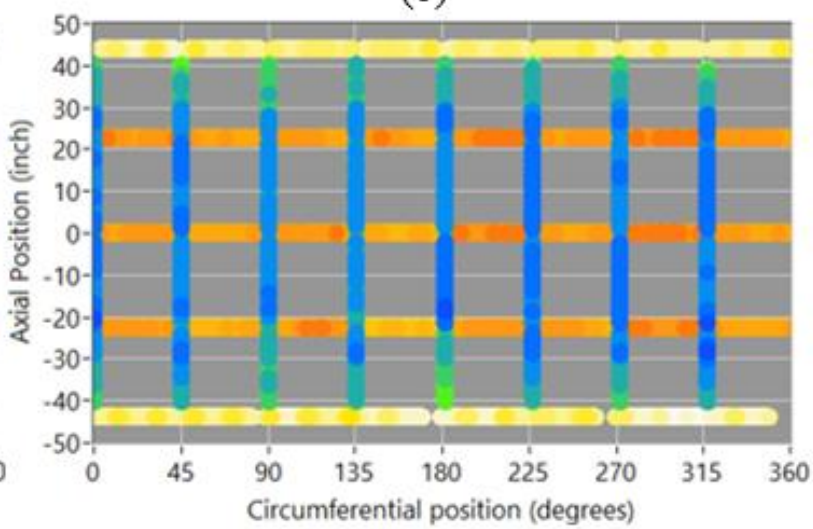

(d)

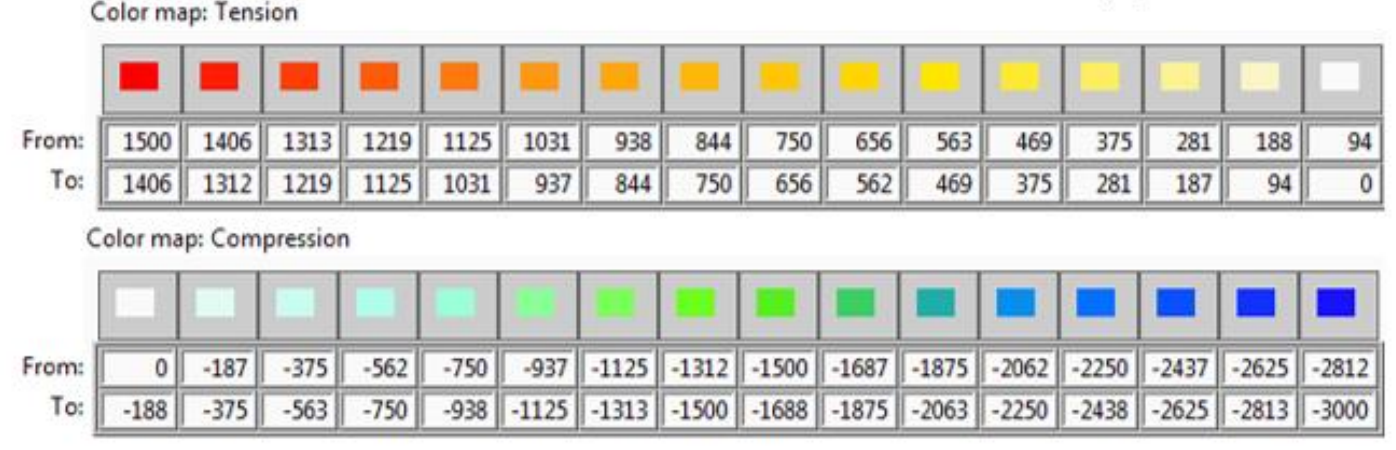

(e)

Fig. 10. Distributed strain measurements on the inner mold line during axial compression load cases: (a) $20 \% P_{c r}$, (b) $30 \% P_{c r}$, (c) $40 \% P_{c r}$, (d) $50 \% P_{c r}$, and (e) microstrain color scale.

During the combined compression and bending load sequences, compressive loads were highest at specific circumferential positions and tapered linearly to zero at the $180^{\circ}$ circumferential offset. The FOSS results from combined bending and compression load sequences with maximum compression at $0^{\circ}, 90^{\circ}, 180^{\circ}$, and $270^{\circ}$ are presented in Fig. 11(a)-(e) for average compressive loads of 20\% Pcr. The use of a 2D scatter plot with a color map indicating strain level enabled engineers to quickly and efficiently examine the strain state of structure in real time. 


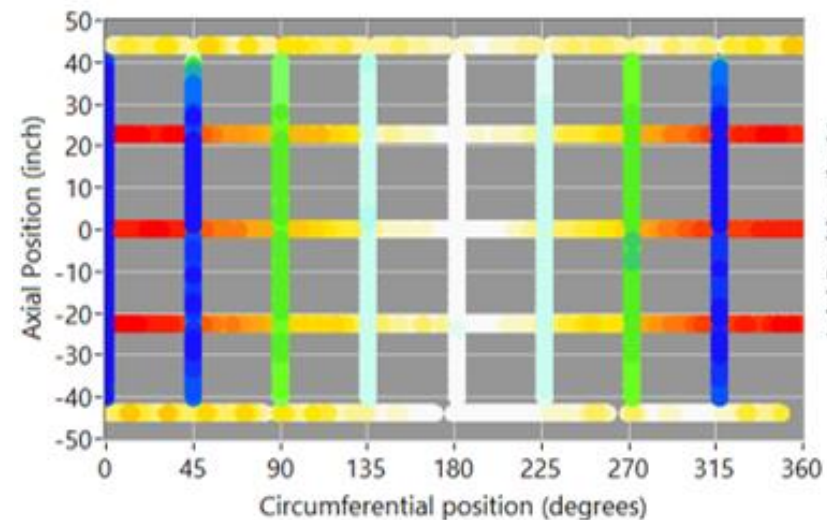

(a)

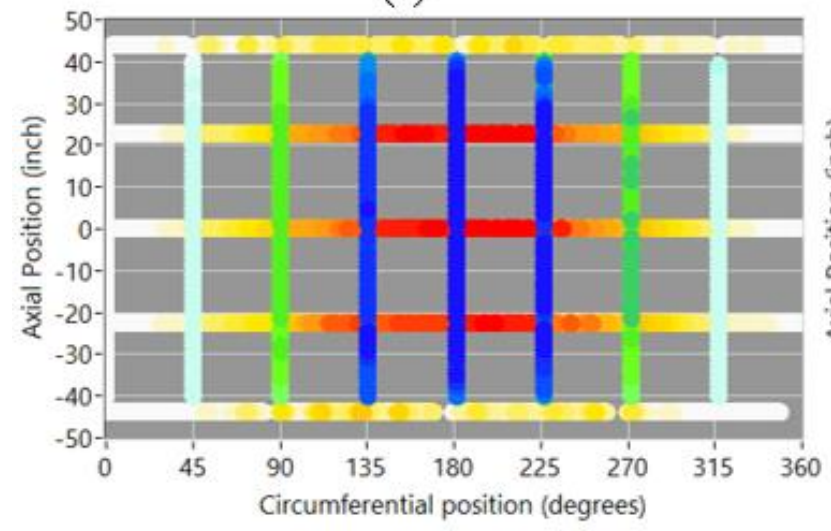

(c)

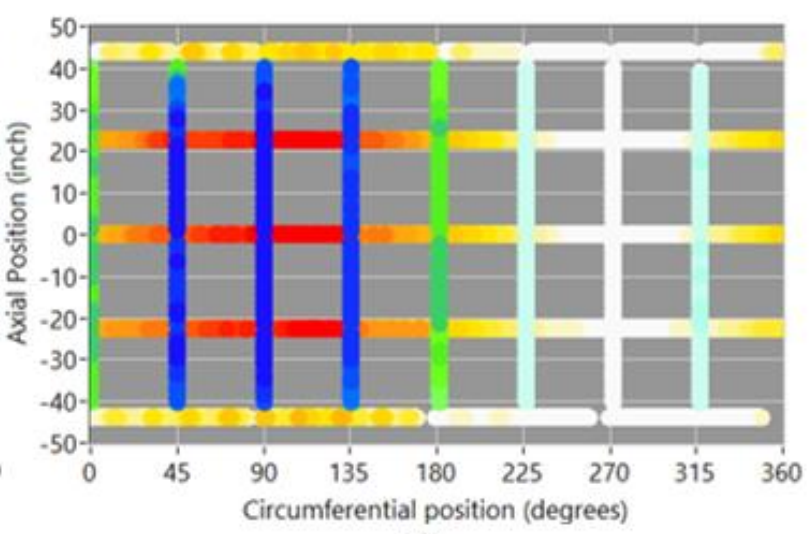

(b)

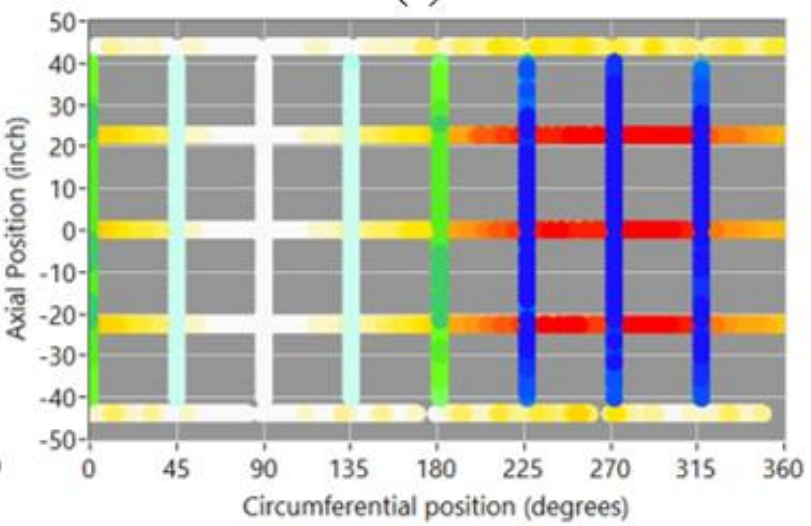

(d)

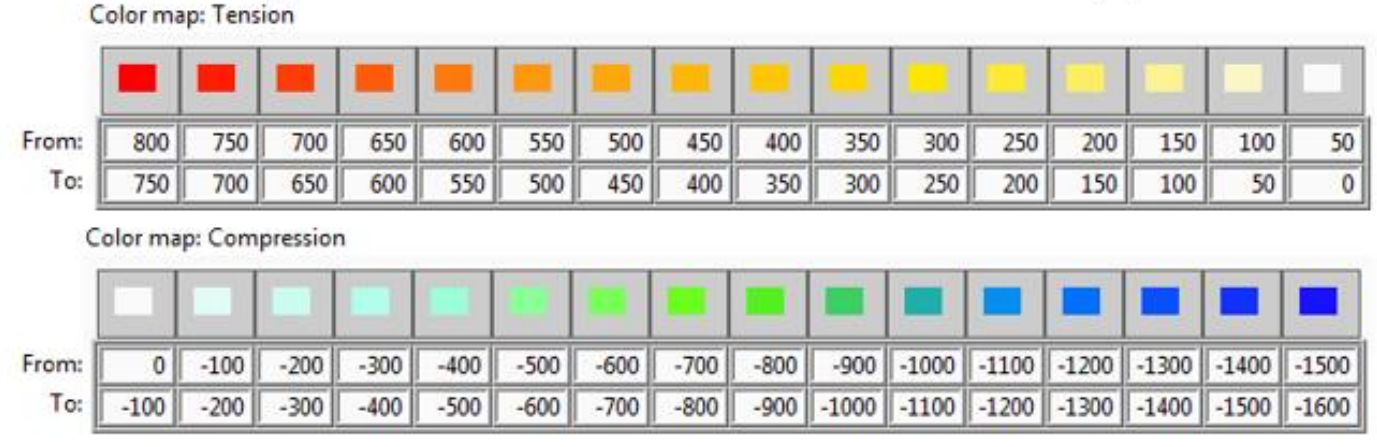

(e)

Fig. 11. Distributed strain measurement on the inner mold line during simulated compression and bending load cases with maximum applied compression at: (a) $0^{\circ}$ circumferential position, (b) $90^{\circ}$ circumferential position,

(c) $180^{\circ}$ circumferential position, (d) $270^{\circ}$ circumferential position, and (e) microstrain color scale.

\subsection{Axial Compression to Failure}

During the final load sequence, uniform axial compression load was slowly applied to CTA8.1 until catastrophic buckling occurred. The test article failed at $856,900 \mathrm{lbf}$. The FOSS strain distribution on the OML and IML incipient to failure is presented in Fig. 12. It is evident from this figure that the axial strains were not nearly as uniformly distributed as shown in Fig. 10 in the axial compression load cases at lower percentages of $P_{c r}$. This difference is due to non-uniform prebuckling deformations that grow with increasing loads. 


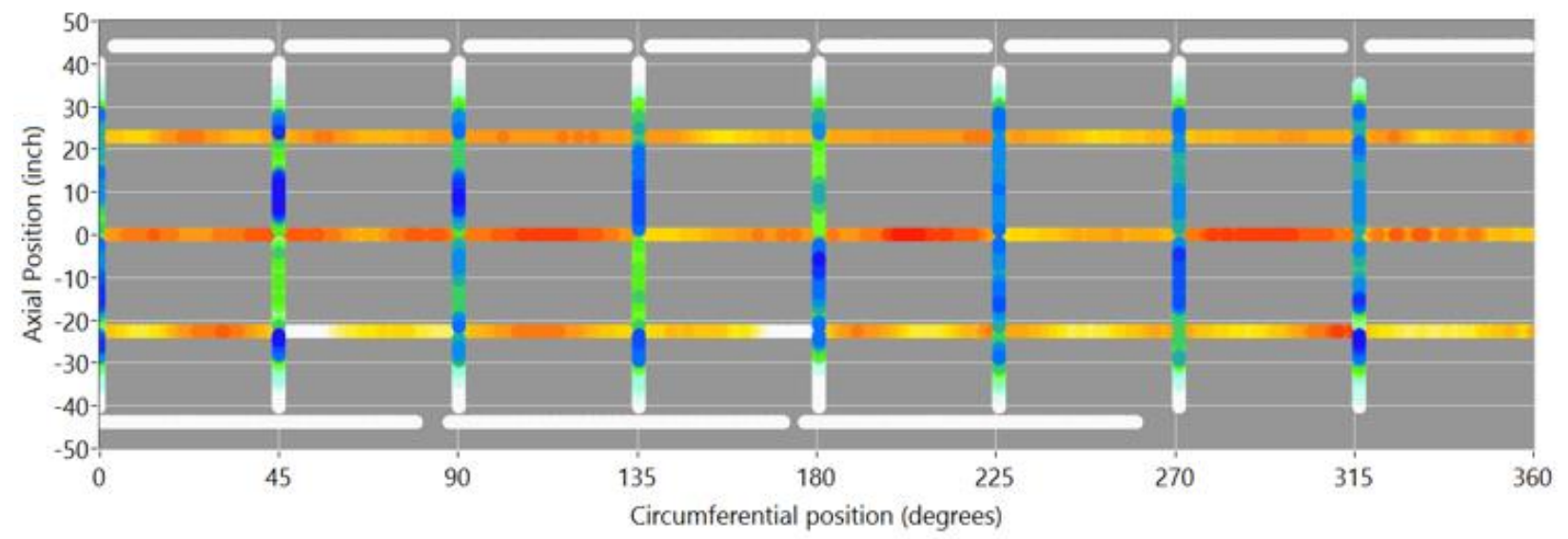

(a)

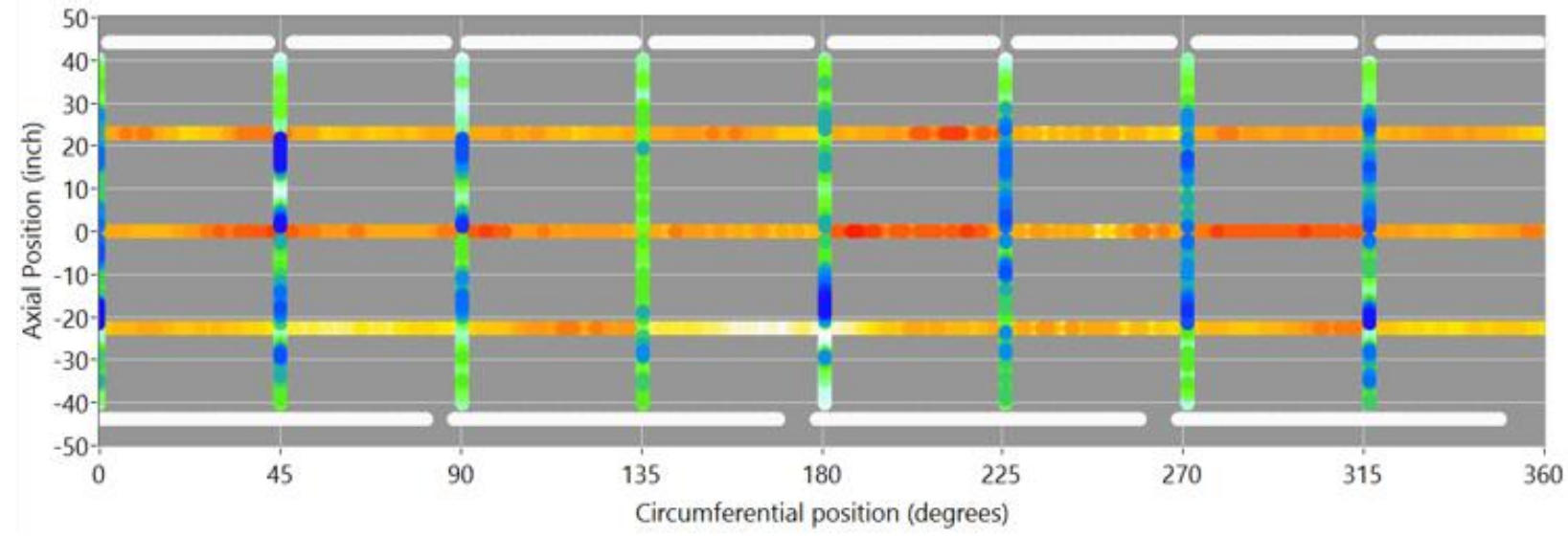

(b)

Color map: Tension

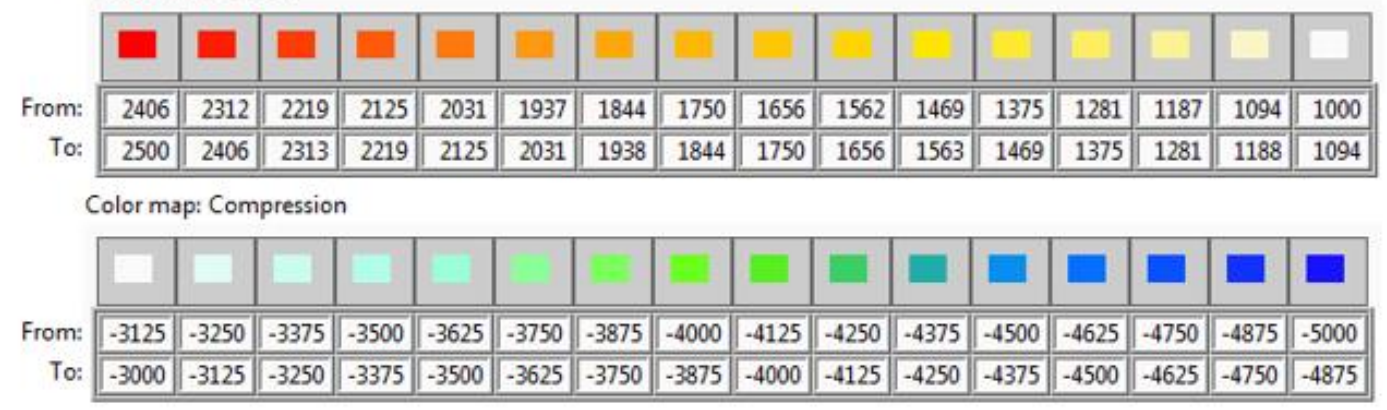

(c)

Fig. 12. Distributed strain measurement at $856,900 \mathrm{lbf}$ compression, incipient to failure: (a) outer mold line, (b) inner mold line, and (c) strain color scale.

During shell buckling tests, one of the key parameters to monitor is the bending strain, $\varepsilon_{b}$, because it can be an indication of the localization of radial deformations leading to buckling. To monitor bending strains for the SBKF project, the IML and OML sensors were collocated to within 0.5 inch (circumferentially and axially) and the bending strains were calculated as one-half of the difference between these IML and OML strain measurements, as shown in Eq. (4):

$$
\varepsilon_{b}=\frac{\varepsilon_{O M L, i}-\varepsilon_{I M L, i}}{2}
$$


where $\varepsilon_{O M L, i}$ is the strain on the OML at the $i$ th index station and $\varepsilon_{\mathrm{IML}, \mathrm{i}}$ is the strain on the IML at the $i$ th index. An image of the FOSS-calculated bending strains incipient to failure is presented in Fig. 13(a) and (b). In the absence of bending deformations in the cylinder wall during loading, the bending strains are zero, but when bending deformations begin to occur, the bending strains begin to grow in magnitude. Figure 13 shows that the maximum bending strain monitored by the FOSS just before failure was at the $45^{\circ}$ circumferential position, and approximately 10 inches above the mid-height of the cylinder.

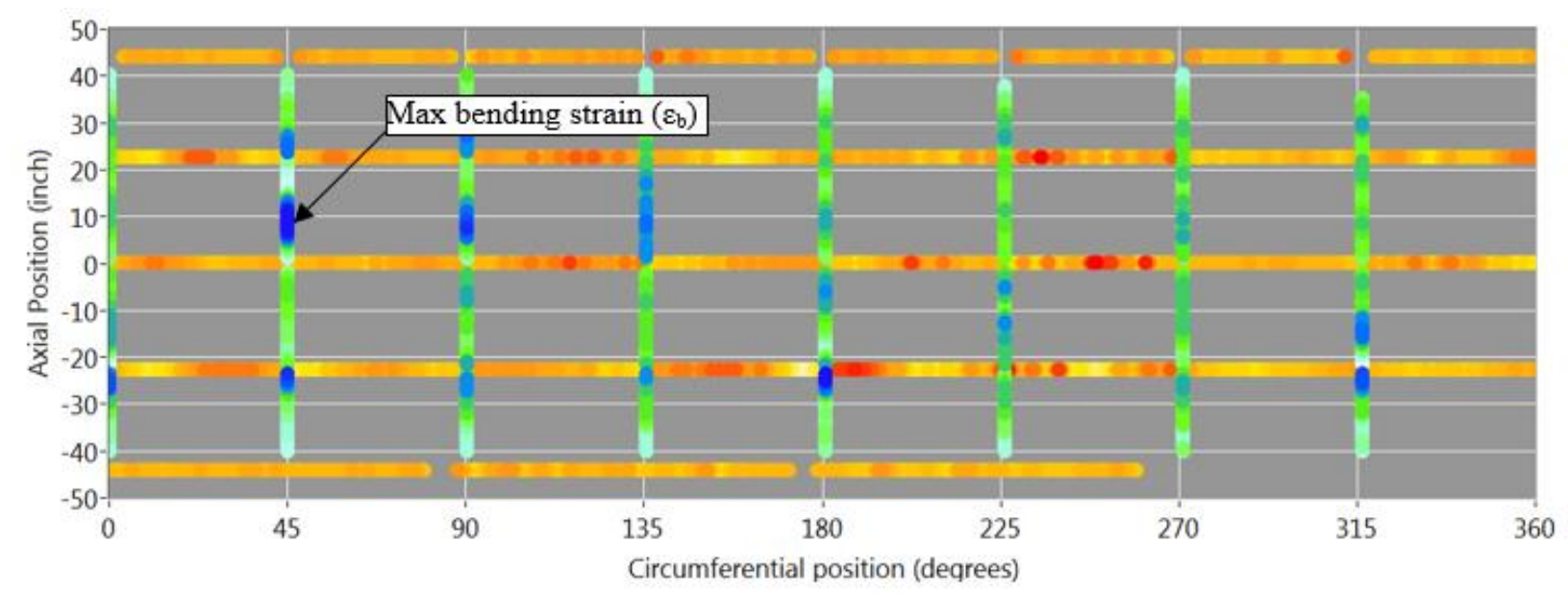

(a)

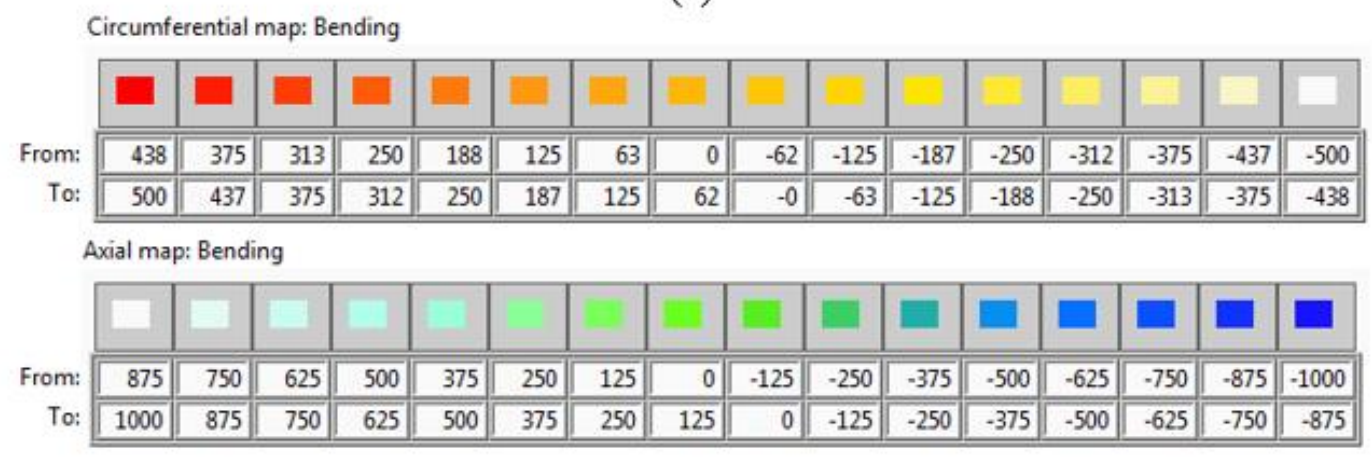

(b)

Fig. 13. (a) distributed bending-strain measurements at maximum load incipient to failure, and (b) bending-strain intensity color scale.

Data captured from the high-speed DIC system provided additional evidence of the failure location for CTA8.1. Just before failure, the largest radial displacement was from an inward-facing dimple located at $45^{\circ}$ in the circumferential coordinate and positive 10 inches above the mid-length of the barrel, which was moving inward faster than at any other location. The low-speed DIC results just prior to failure are presented in Fig. 14, where $w$ is the radial displacement in inches. The high-speed DIC was able to capture the material rupture after loss of stability at the same location as the maximum bending strain measured from FOSS during failure. 


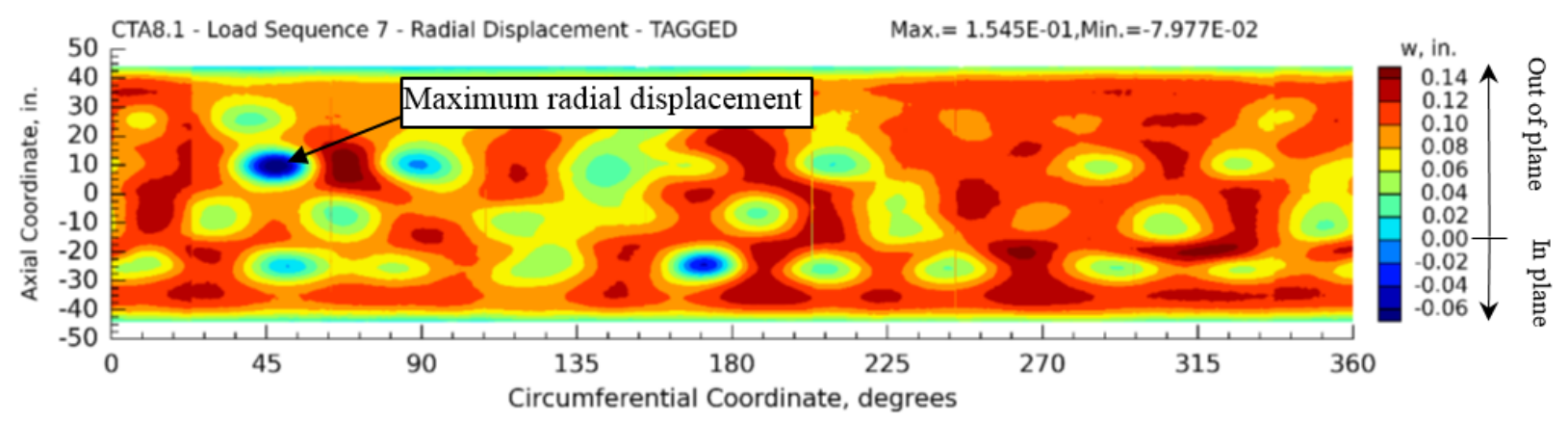

Fig. 14. Low-speed digital image correlation, outer mold line view, radial displacement contour plot incipient to failure.

The combination of high density and the continuous nature of the distributed fiber optic sensing technology also enabled a comparison between the radial displacements captured by the DIC to the distributed bending-strain measurements. A comparison of the FOSS bending strain overlaid on the DIC radial displacement contour is presented in Fig. 15(a) and (b).

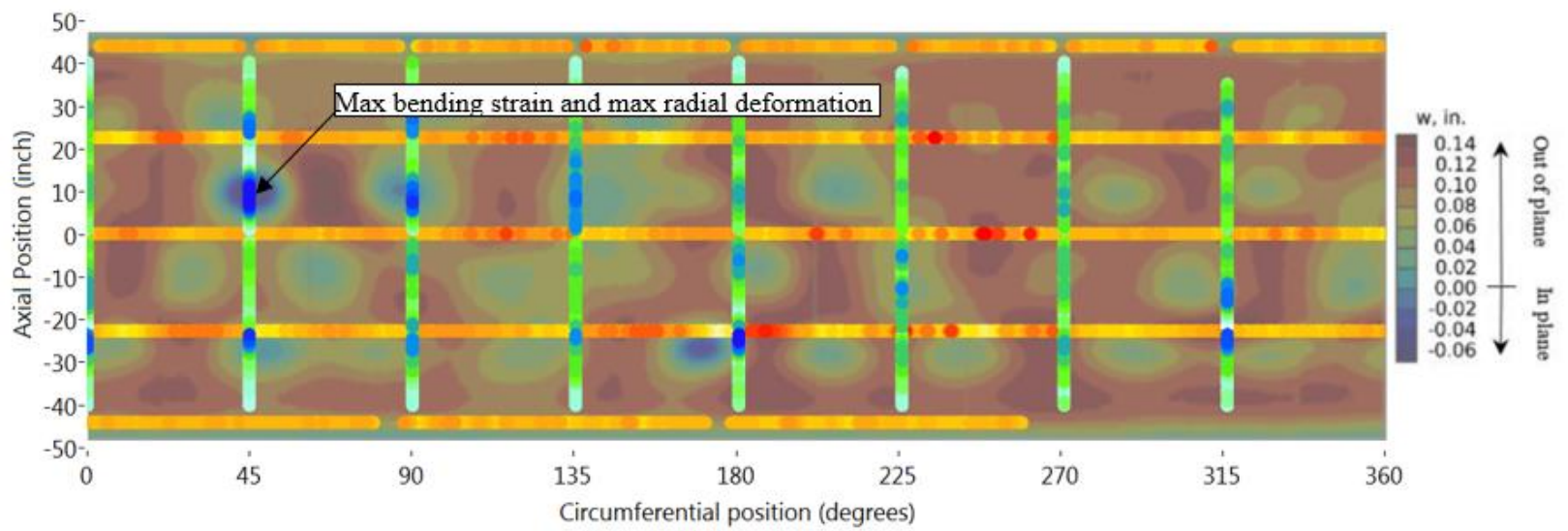

(a)

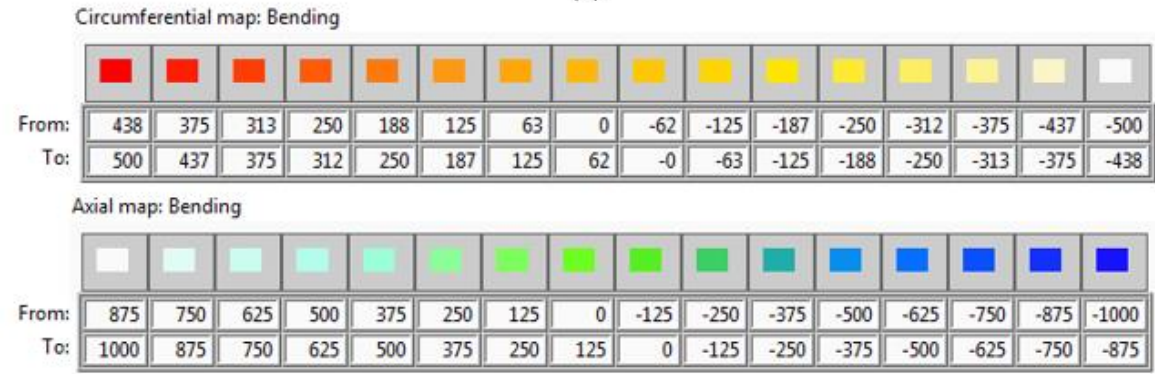

(b)

Fig. 15. (a) fiber optic sensing system bending strain overlaid on digital image correlation outer mold line radial displacement contour incipient to failure, and (b) bending-strain intensity color scale.

The load time history and the FOSS time histories of the OML and IML axial strains at the point of maximum bending strain identified in Fig. 13(a) and (b) and Fig. 15(a) and (b) are shown in Fig. 16. The left-hand vertical axis scale is the axial strain in microstrain for the OML (blue) and IML (green) FOSS measurements. The right-hand vertical axis scale is the indication of the magnitude of applied load (red). It can be seen in the figure that the OML and IML strains begin to deviate from one another at higher load levels due to the bending caused by the onset of buckling. 


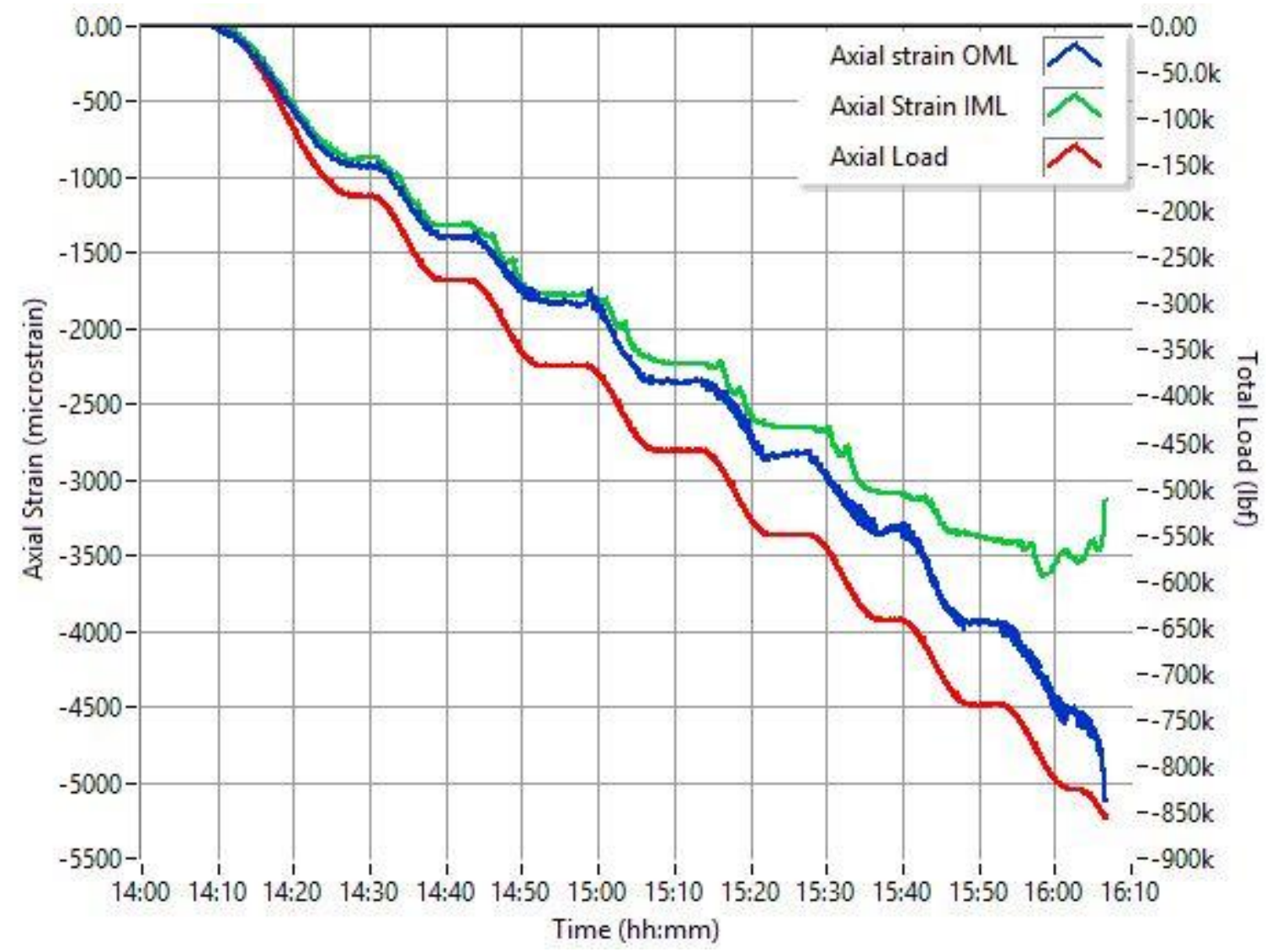

Fig. 16. Time history of outer mold line (blue) and inner mold line (green) axial strains at the location of maximum bending strain as compared to axial applied load (red).

The time history of the bending strain calculated at the point of maximum bending strain is presented in Fig. 17. The left-hand vertical axis scale is bending strain (purple) and the right-hand vertical axis the magnitude of applied load (red). It can be seen that the bending strains grow more rapidly as load increases, which leads to the large radial deformation and, ultimately, to the sudden collapse of the test article. 


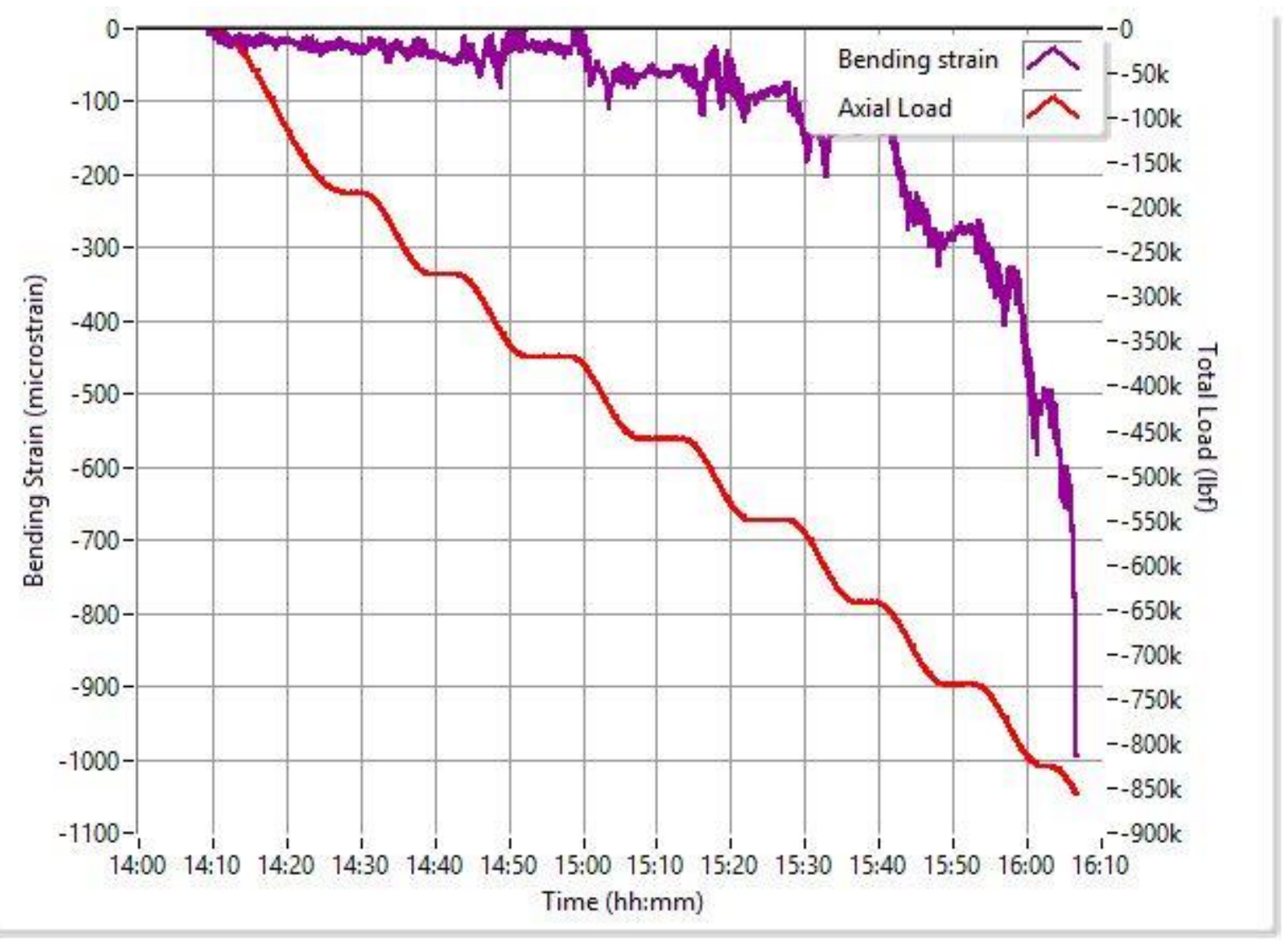

Fig. 17. Time history of bending strain (purple) at location of maximum bending strain as compared to axial applied load (red).

\section{Concluding Remarks}

The NASA Armstrong Flight Research Center (Edwards, California) -developed fiber optic sensing system (FOSS) was used to measure strains in a recent large-scale sandwich composite cylinder buckling test. Specifically, the FOSS was used for the Shell Buckling Knockdown Factor Project to provide real-time monitoring and post-test evaluation of both the circumferential and axial strain fields and the buckling response of the cylinder under compressive and combined compressive and bending loads. The experimental data were obtained through a network of five near-continuous axial stations along the height of the structure and eight near-continuous circumferential stations of fiber Bragg gratings distributed on both the outer mold line and the inner mold line of the cylinder, and provided nearly 16,000 individual strain measurements. The distributed fiber Bragg gratings covered a large area of the test article and provided engineers with real-time monitoring of the structural response of the test article. The large coverage area increased the probability of capturing bending strain during buckling; pre-test buckling predictions and actual buckling may vary, making it challenging to locate conventional surface-mounted instrumentation. The FOSS provided 144 qualitative rosette measurements to monitor the boundary conditions and load introduction near the loading-ring attachment points. The FOSS data were compared to audio data collected by a microphone to help determine the location and cause of a series of "popping" noises heard during the subcritical compression loads, and to determine how the structure was affected. The real-time graphical representation of high-density strain maps provided an efficient and effective process for monitoring the strain response over a large section of the test article. The FOSS data supplemented the use of digital image correlation techniques by providing localized bending-strain data at the point of maximum deflection leading up to the collapse of the test article. 


\section{References}

[1] Schultz, M. R., Sleight, D. W., Gardner, N. W., Rudd, M. T., Hilburger, M. W., Palm, T. E., and Oldfield, N. J., "Test and Analysis of a Buckling-Critical Large-Scale Sandwich Composite Cylinder," to be presented at the AIAA/ASCE/AHS/ASC Structures, Structural Dynamics and Materials Conference, Kissimmee, FL, January 2018 (submitted for publication).

[2] Richards, W. L., Parker, A. R., Ko, W. L., Piazza, A., Chan, P. Application of Fiber Optic Instrumentation, RTO-AG-160-V22, 2012.

[3] Dally, J. W., and Riley, W. F., Experimental Stress Analysis, ${ }^{\text {rd }}$ ed., McGraw-Hill, Inc., New York, 1991, Chaps. 1, 9.

[4] Gere, J. M., Mechanics of Materials, $6^{\text {th }}$ ed., Brooks/Cole, California, 2004, Chap. 7. 